\title{
Changes in Insulin-like Growth Factor-1 Level in Patients with Sepsis and Septic Shock
}

\author{
Sang Hoon Lee, M.D. ', Byung Hoon Park, M.D. ${ }^{2}$, Joo Han Song, M.D. ${ }^{2}$, Song Yee Kim, M.D., Ph.D. ${ }^{2}$, \\ Kyung Soo Chung, M.D. ${ }^{2}$, Eun Young Kim, M.D., Ph.D. ${ }^{2}$, Ji Ye Jung, M.D. ${ }^{2}$, Young Sam Kim, M.D., Ph.D. ${ }^{2}$, \\ Se Kyu Kim, M.D., Ph.D. ${ }^{2}$, Joon Chang, M.D., Ph.D. ${ }^{2}$, and Moo Suk Park, M.D., Ph.D. ${ }^{2}$ \\ ${ }^{1}$ Division of Pulmonary and Critical Care Medicine, Department of Internal Medicine, Seoul National University Bundang Hospital, Seoul National University College of Medicine, Seongnam; \\ ${ }^{2}$ Division of Pulmonary and Critical Care Medicine, Department of Internal Medicine, Institute of Chest Diseases, Severance Hospital, Yonsei University College of Medicine, Seoul, Korea
}

Background: Despite many ongoing, prospective studies on the topic, sepsis still remains one of the main causes of death in hospital. The hormone insulin-like growth factor 1 (IGF-1) has a similar molecular structure to that of insulin. IGF-1 exerts anabolic effects and plays important roles in both normal physiology and pathologic processes. Previous studies have observed low serum IGF-1 level in patients with critical illnesses. Here, we evaluated changes in IGF-1 level based on survival of septic patients.

Methods: We evaluated 140 patients with sepsis and septic shock ( 21 with sepsis and 119 with septic shock) admitted to the intensive care unit of a university-affiliated hospital in Korea. Serum IGF-1 level was measured on days 0, 1, 3, and 7. Patients with liver disease were excluded from this study. All data were analyzed using SPSS version 20 (SPSS Inc., Chicago, IL, USA).

Results: Patients with septic shock had significantly lower serum IGF-1 level on days 1 and 3 than patients without septic shock ( $p=$ 0.002 and $p=0.007$, respectively). Generally, there was a negative relationship between IGF- 1 and serum cortisol levels; however, this relationship was only significant on day $3(p=0.029)$. Furthermore, renin showed significantly negative correlation with IGF-1 on day 3 ( $p=0.038$ ). IGF-1 level did not show significant difference between survivors and non-survivors.

Conclusions: Our results showed that IGF-1 was associated with septic shock, and that the IGF-1 axis is severely disrupted in septic patients. Additionally, serum cortisol and renin levels were associated with IGF-1 level.

Key Words: insulin-like growth factor-1; sepsis.

\section{Introduction}

Sepsis is one of the most common causes of death in the medical intensive care unit (ICU).[1] Recently, large-scale, prospective studies of early goal-directed therapy failed to demonstrate any improvement in the mortality.[2-4] Although many trials have been conducted, the global mortality rate remains high, ranging from $24.0 \%$ to $30.0 \%$ for sepsis and from $40.0 \%$ to $70.0 \%$ for septic shock.[5,6]

Received on January 14, 2016 Revised on July 20, 2016 Accepted on August 19, 2016

Correspondence to: Moo Suk Park, Division of Pulmonology and Critical Care Medicine, Department of Internal Medicine, Institute of Chest Diseases, Severance Hospital, Yonsei University College of Medicine, 50-1 Yonsei-ro, Seodaemun-gu, Seoul 03722, Korea

Tel: +82-2-2228-1955, Fax: +82-2-393-6884

E-mail: pms70@yuhs.ac

*No potential conflict of interest relevant to this article was reported.
During sepsis, the hypothalamic-pituitary-adrenal axis (HPA) is activated, leading to the release of adrenocorticotrophic hormone. Activation of the HPA axis and release of cortisol are important steps in maintaining homeostasis in organs affected by sepsis.[7] Stress induced by critical illness leads to a sympathoadrenal response. In this type of response, the pituitary plays an important role in both im- 
munologic and metabolic homeostasis.[8] Stimulation of the pituitary gland by critical illness leads to the pulsatile release of growth hormone $(\mathrm{GH})$ and insulin-like growth factor-1 (IGF-1) into the plasma; however, prolonged sepsis gradually but significantly decreases the release of these hormones.[9] The more severe is the sepsis, the greater is the decrease in the levels of these hormones.[9] Previous studies showed mixed clinical results regarding the influence of GH/IGF-1. Some studies showed clinically positive effects of GH/IGF-1 administration in septic and surgical patients (improved nitrogen balance, maintenance of GH/IGF-1 level, increased bursting pressure of anastomosis, and prevention of gut barrier failure), whereas other studies reported no changes or even increased mortality in association with GH administration.[10-14]

Although the changes in serum GH/IGF-1 level under septic or surgical conditions have been studied previously, changes in these hormones over time have not been well-evaluated. Moreover, most previous studies regarding GH/IGF-1 were performed in Western countries. As such, additional studies are needed to investigate the role of GH in an Asian population. Furthermore, previ- ous studies analyzed the interaction between IGF-1 and the cortisol or renin-angiotensin system in the context of diabetes mellitus or cardiovascular disease.[15-18]

We aimed to investigate the differences and change over time in serum IGF-1 level in medical ICU patients with or without septic shock on days 0 (day of admission), 1, 3, and 7 to determine whether IGF-1 is associated with a better prognosis. Furthermore, we investigated the relationships of renin and cortisol with IGF-1 in patients with sepsis.

\section{Materials and Methods}

\section{1) Study populations}

This study was performed in the medical ICU of Severance Hospital, a 2,500-bed university medical center in Seoul, South Korea. The medical ICU is a 30-bed closed unit, managed by certified ICU specialists who care only for ICU patients. The cardiac ICU is operated separately. All patients admitted to the medical ICU were enrolled in this study from August 2008 to December 2008.

In this study, sepsis was defined as a systemic response

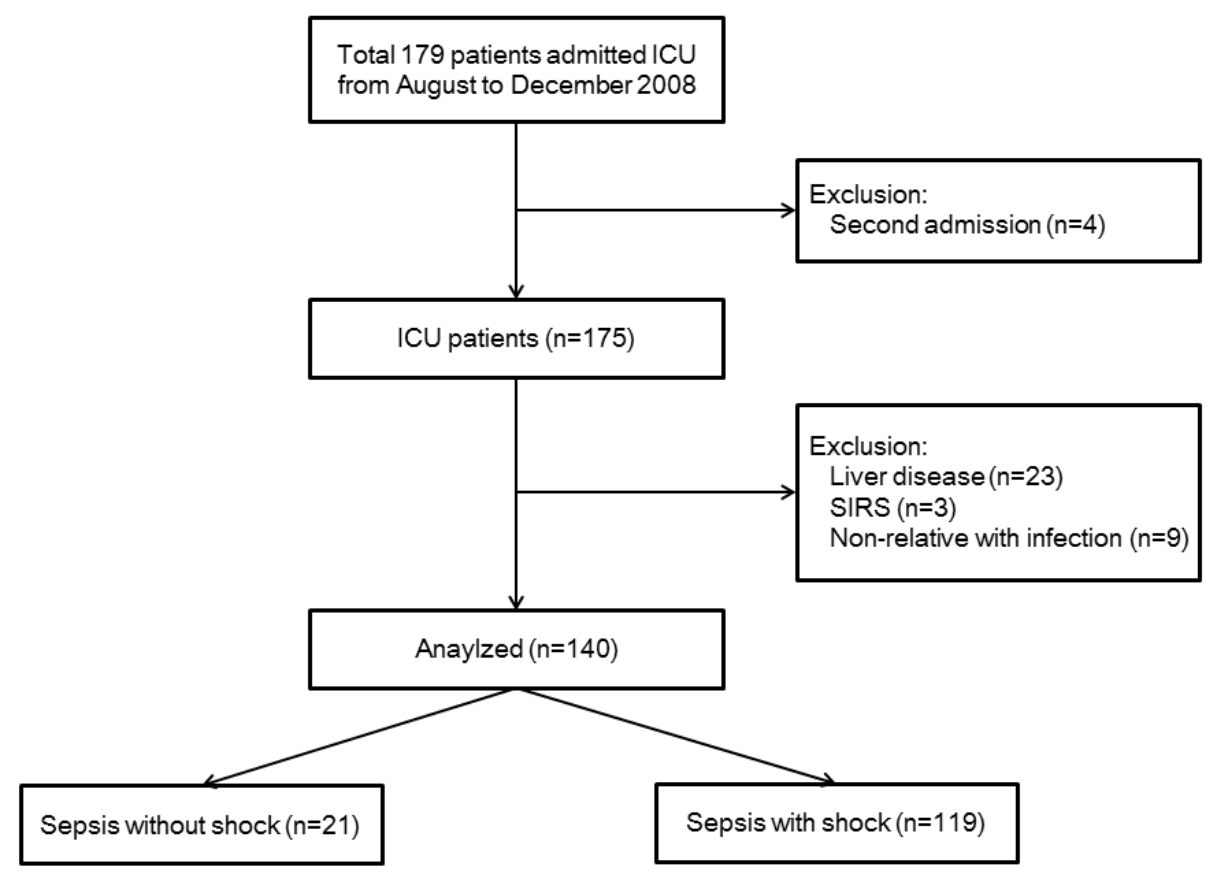

Fig. 1. Flow chart of the study population. Initially, 179 intensive care unit (ICU) patients were enrolled from August to December 2008. The following patients were excluded: patients who were being admitted for a second time $(n=4)$, patients with liver disease $(n=23)$, patients diagnosed with systemic inflammatory response syndrome (SIRS) $(n=3)$, and patients with noninfectious disease $(n=9)$. 
to infection that met three of the four criteria for systemic inflammatory response syndrome: (1) body temperature less than $36^{\circ} \mathrm{C}$ or greater than $38^{\circ} \mathrm{C}$; (2) heart rate greater than 90 beats per minute; (3) respiratory rate greater than 20 breaths per minute or a $\mathrm{PaCO}_{2}$ less than $32 \mathrm{mmHg}$; and (4) white blood cell count less than 4,000 cells $/ \mathrm{mm}^{3}$ or greater than 12,000 cells $/ \mathrm{mm}^{3}$. Septic shock was defined as sepsis-related persistent hypotension, despite adequate fluid resuscitation.[19] A total of 179 ICU patients were initially enrolled. Patients were excluded if they were younger than 18 years of age, pregnant, or readmitted to the ICU during their hospital stay. Patients who required primary cardiac treatment, had liver disease (e.g., immune hepatitis, hepatitis $\mathrm{B} / \mathrm{C}$, liver cirrhosis, hepatocellular carcinoma), or did not meet the criteria for sepsis were also excluded. Finally, 140 ICU patients were analyzed; 21 patients had sepsis without shock, and 119 patients had sepsis with shock (Fig. 1).

The guidelines of the Surviving Sepsis Campaign were used for management of the study population.[20] For each patient, age, sex, body mass index (BMI), $\mathrm{PaO}_{2} /$ $\mathrm{FiO}_{2}$ ratio, infection site, comorbidity, length of ICU stay, and 28-day mortality were investigated. Various laboratory parameters, including IGF-1 level, were analyzed on days 0 (day of ICU admission), 1, 3, and 7. Additionally, Acute Physiology and Chronic Health Evaluation (APACHE) II and Sequential Organ Failure Assessment (SOFA) scores were calculated.

\section{2) Blood sampling and assays}

After admission to the medical ICU (day 0), arterial catheterization was performed by a resident physician. Initial blood samples were obtained immediately using an indwelling arterial catheter. The remaining blood samples (days 1, 3, and 7) were obtained at 5:00 AM for all eligible patients. Serum IGF-1 level and renin were measured using a commercial radioimmunoassay kit (Diasorin, Stillwater, MN, USA). Cortisol level was measured with a competitive binding immunoenzymatiic assay kit (Beckman Coulter, Miami, FL, USA).

\section{3) Statistical analysis}

The Mann-Whitney $U$ test or Student's $t$-test was used for analysis depending on data distribution. Quantitative data are reported as median with interquartile range or mean \pm standard deviation. Fisher's exact test or Pearson's 2 test was used for the analysis of categorical variables, which are reported as absolute frequencies and percentages. After adjusting for age, sex, and BMI, a linear mixed model was used to analyze changes in IGF-1 level over time in septic patients with or without shock. Pearson's correlation analyses were performed to evaluate relationships between cortisol, renin, aldosterone, glucagon, and IGF-1 level. The effect of IGF-1 on 28-day mortality after adjusting for age, sex, and BMI was analyzed using Cox proportional hazards regression models. All statistical analyses in this study were conducted using SPSSTM version 20 software (SPSS Inc., Chicago, IL, USA). An adjusted p-value $<0.05$ was defined as statistically significant.

\section{4) Ethics statement}

The study protocol was reviewed and approved by the Institutional Review Board of Yonsei University Health Service, Severance Hospital (IRB approval No. 4-20080099). Written consent was obtained from the patients or their relatives.

\section{Results}

Table 1 shows the baseline characteristics of the study population $(n=140)$ on the day of admission. The mean age of the enrolled patients was $62.3 \pm 16.0$ years, and the mean BMI was $23.1 \pm 4.0 \mathrm{~kg} / \mathrm{m}^{2}$. Age, sex, BMI, and length of ICU stay did not significantly differ between septic patients with shock and those without shock. Patients with septic shock had significantly elevated APACHE II and SOFA scores relative to those of sepsis patients without shock $(\mathrm{p}=0.008$ and $<0.001$, respectively). The most common infection site was lung $(83.6 \%)$ followed by abdomen (10.0\%) in both groups, and the 
Table 1. Baseline characteristics of patients at ICU admission $(n=140$, day 0$)$

\begin{tabular}{|c|c|c|c|}
\hline Variables & $\begin{array}{l}\text { Sepsis without shock } \\
\qquad(\mathrm{n}=21)\end{array}$ & $\begin{array}{l}\text { Sepsis with shock } \\
\quad(n=119)\end{array}$ & $\mathrm{p}$-value \\
\hline Age (yr) & $58.2 \pm 18.1$ & $63.0 \pm 15.5$ & 0.203 \\
\hline Male & 16 (76.2) & $70(58.8)$ & 0.132 \\
\hline $\mathrm{BMI}\left(\mathrm{kg} / \mathrm{m}^{2}\right)$ & $23.0 \pm 3.7$ & $23.1 \pm 4.1$ & 0.962 \\
\hline Length of ICU stay (days) & $7.0[4.5,14.5]$ & $11.0[5.0,21.0]$ & 0.147 \\
\hline APACHE II score & $16.2 \pm 6.6$ & $19.7 \pm 5.1$ & 0.008 \\
\hline SOFA score & $4.3 \pm 2.1$ & $8.2 \pm 3.5$ & $<0.001$ \\
\hline $\mathrm{PaO}_{2} / \mathrm{FiO}_{2}(\mathrm{mmHg})$ & $266.3 \pm 136.6$ & $212.8 \pm 110.7$ & 0.051 \\
\hline Infection site & & & 0.932 \\
\hline Lung & $17(81.0)$ & $100(84.0)$ & \\
\hline Urinary tract & $1(4.8)$ & $4(3.4)$ & \\
\hline Abdomen & $2(9.5)$ & $12(10.1)$ & \\
\hline Others & $1(4.8)$ & $3(2.5)$ & \\
\hline \multicolumn{4}{|l|}{ Underlying diseases } \\
\hline Diabetes mellitus & $3(14.3)$ & $32(26.9)$ & 0.219 \\
\hline Chronic lung disease* & $5(23.8)$ & $24(20.2)$ & 0.704 \\
\hline Chronic renal disease & $4(19.0)$ & $17(14.3)$ & 0.522 \\
\hline Hypertension & $10(47.6)$ & $47(39.5)$ & 0.485 \\
\hline Heart failure & $5(23.8)$ & $12(10.1)$ & 0.137 \\
\hline Coronary artery disease & $2(9.5)$ & $13(10.9)$ & 1.000 \\
\hline Mortality & $1 / 20(4.8)$ & 62/57 (52.1) & $<0.001$ \\
\hline
\end{tabular}

Data are presented as mean \pm SD or numbers (percentages).

ICU: intensive care unit; BMl: body mass index; APACHE II: Acute Physiology and Chronic Health Evaluation II; SOFA: Sequential Organ Failure Assessment.

${ }^{*}$ Chronic lung disease includes asthma, chronic obstructive pulmonary disease, and structural lung diseases, such as bronchiectasis and interstitial lung disease.

differences between the groups were not significant ( $\mathrm{p}$ $=0.932$ ). Comorbidities were not significantly different between the groups. Understandably, mortality was significantly higher in patients with septic shock $(\mathrm{p}<0.001)$.

Many of the laboratory results at admission are listed in Table 2. Hemoglobin level, platelet count, and renal function (blood urea nitrogen and creatinine levels) did not differ significantly between the groups ( $p=0.741$, $0.794,0.457$, and 0.924 , respectively). Among patients with sepsis, shock was associated with significantly elevated C-reactive protein level and significantly reduced albumin level ( $\mathrm{p}=0.007$ and 0.004 , respectively). A not significant difference in serum IGF-1 level was observed between the groups. Furthermore, there were no significant differences in serum levels of many other hormones on the day of ICU admission.

Fig. 2 shows the changes in serum IGF-1, cortisol, and renin levels over time from the day of ICU admission to ICU day 7. After adjusting for age, sex, and BMI, these changes did not differ significantly between septic patients with shock and those without $(\mathrm{p}=0.277,0.208$, and 0.165 , respectively). However, significant differences in mean IGF-1 level were observed on days 1 and 3 ( $p$ $=0.002$ and 0.007 , respectively). In addition, the groups differed significantly in serum cortisol level on days 1, 3 , and 7 and in serum renin level on day 3. A Cox pro- 
Table 2. Laboratory data of patients at ICU admission $(n=140$, day 0$)$

\begin{tabular}{|c|c|c|c|}
\hline Variables & $\begin{array}{l}\text { Sepsis without shock } \\
\qquad(\mathrm{n}=21)\end{array}$ & $\begin{array}{l}\text { Sepsis with shock } \\
\qquad(n=119)\end{array}$ & $\mathrm{p}$-value \\
\hline Hemoglobin (g/dL) & $10.1 \pm 2.7$ & $9.9 \pm 2.2$ & 0.741 \\
\hline Platelets $\left(10^{3} / \mathrm{mm}^{3}\right)$ & $201.0 \pm 118.8$ & $191.6 \pm 157.2$ & 0.794 \\
\hline Blood urea nitrogen (mg/dL) & $26.9 \pm 20.4$ & $31.3 \pm 25.3$ & 0.457 \\
\hline Creatinine (mg/dL) & $1.9 \pm 2.1$ & $1.9 \pm 2.2$ & 0.924 \\
\hline $\mathrm{CRP}(\mathrm{mg} / \mathrm{dL})$ & $14.0 \pm 7.1$ & $19.5 \pm 12.9$ & 0.007 \\
\hline Albumin (mg/dL) & $3.1 \pm 0.7$ & $2.6 \pm 0.6$ & 0.004 \\
\hline Cholesterol (mg/dL) & $128.2(112.5,148.5)$ & $97.1(63.0,120.0)$ & 0.004 \\
\hline Triglyceride (mg/dL) & $179.1(62.0,302.3)$ & $106.8(61.3,130.3)$ & 0.152 \\
\hline IGF-1 (ng/mL) & $96.5(46.6,137.0)$ & $47.9(27.8,89.9)$ & 0.092 \\
\hline Cortisol (ug/dL) & $29.8(15.4,37.7)$ & $31.3(20.2,47.5)$ & 0.213 \\
\hline Renin (ng/mL/hr) & $2.9(0.5,13.9)$ & $4.7(0.9,15.8)$ & 0.941 \\
\hline Aldosterone (pg/mL) & $82.4(44.3,170.3)$ & $89.3(42.9,165.8)$ & 0.962 \\
\hline Glucagon (pg/mL) & $50.5(45.3,61.0)$ & $67.0(42.0 .132 .0)$ & $<0.001$ \\
\hline
\end{tabular}

Data are presented as mean \pm SD or median (interquartile range).

ICU: intensive care unit; CRP: C-reactive protein; IGF-1: insulin-like growth factor-1.

(A)

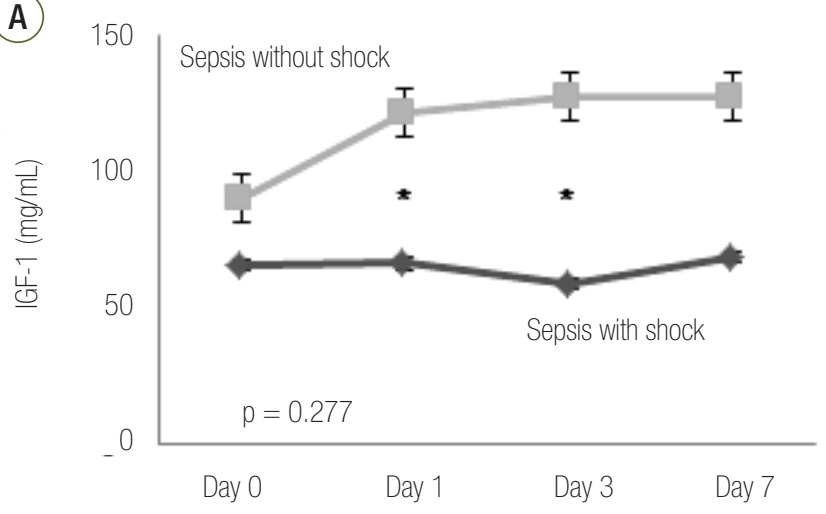

(c)

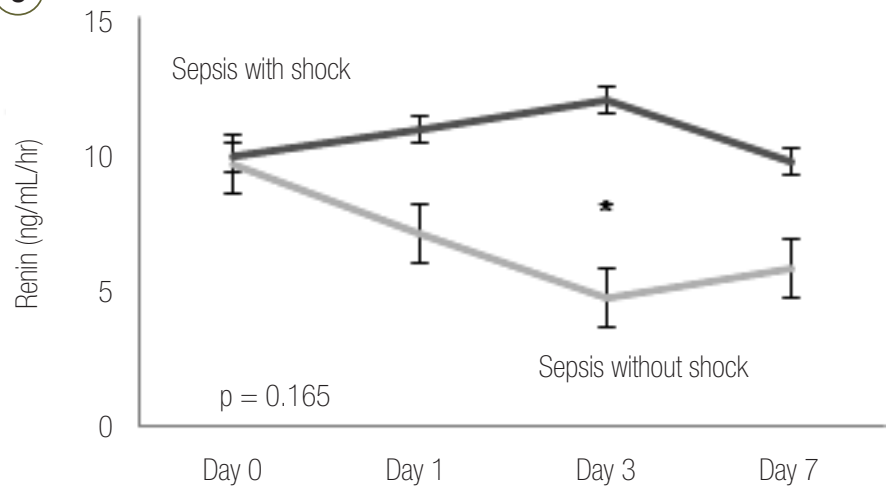

(B)

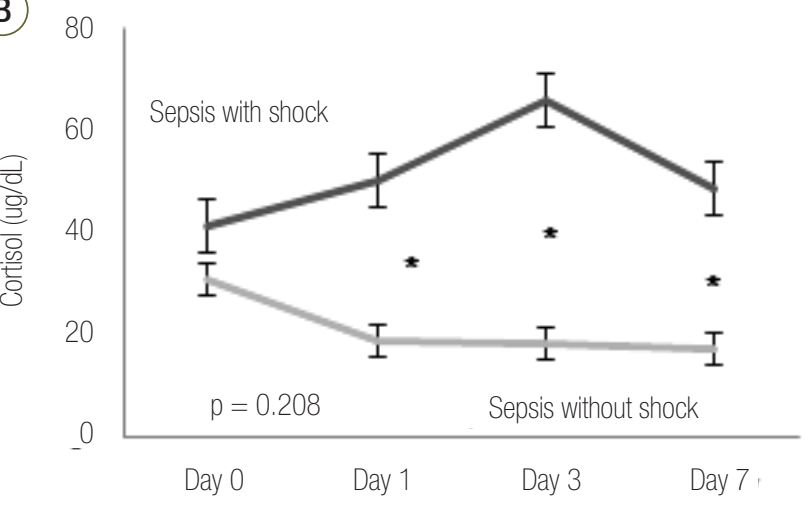

Fig. 2. Time course of insulin-like growth factor (IGF-1), cortisol, and renin levels in patients with sepsis and septic shock. Data for IGF-1 (A), cortisol (B), and renin (C) are shown. The values were examined on the day of admission (day 0 ) and on days 1,3 , and 7 . The circles represent the mean, and the bars represent the standard error of the mean. * ${ }^{*}$ ignificant differences between the sepsis patients and the septic shock patients. 
Table 3. Survival analysis for IGF-1, cortisol, and renin adjusting for age, sex, body mass index, and Sequential Organ Failure Assessment score

\begin{tabular}{|c|c|c|c|c|c|}
\hline \multicolumn{2}{|c|}{ Variables } & \multirow{2}{*}{$\begin{array}{c}\text { Median (IQR) } \\
55.3(30.7,96.9)\end{array}$} & \multirow{2}{*}{$\begin{array}{c}\text { Hazard ratio } \\
1.004\end{array}$} & \multirow{2}{*}{$\begin{array}{c}95 \% \mathrm{Cl} \\
0.996-1.011\end{array}$} & \multirow{2}{*}{$\begin{array}{r}p \text {-value } \\
0.327\end{array}$} \\
\hline Day 0 & IGF-1 & & & & \\
\hline & Cortisol & $31.1(19.5,46.2)$ & 0.997 & $0.990-1.004$ & 0.422 \\
\hline & Renin & $3.8(0.7,15.2)$ & 0.998 & $0.974-1.022$ & 0.871 \\
\hline \multirow[t]{3}{*}{ Day 1} & IGF-1 & $57.8(30.6,104.2)$ & 1.001 & $0.994-1.007$ & 0.805 \\
\hline & Cortisol & $27.4(17.6,47.2)$ & 1.001 & 0.996-1.006 & 0.718 \\
\hline & Renin & $4.0(1.2,14.4)$ & 1.025 & $1.001-1.049$ & 0.042 \\
\hline \multirow[t]{3}{*}{ Day 3} & IGF-1 & $51.4(29.8,91.9)$ & 0.996 & 0.987-1.005 & 0.402 \\
\hline & Cortisol & $23.2(15.0,74.5)$ & 0.998 & $0.994-1.003$ & 0.523 \\
\hline & Renin & $3.1(0.8,20.7)$ & 1.023 & $0.997-1.049$ & 0.084 \\
\hline \multirow[t]{3}{*}{ Day 7} & IGF-1 & $65.7(46.1,95.5)$ & 1.000 & $0.991-1.009$ & 1.000 \\
\hline & Cortisol & $23.9(17.1,49.2)$ & 0.995 & $0.984-1.006$ & 0.381 \\
\hline & Renin & $2.2(0.5,15.1)$ & 1.106 & $1.055-1.160$ & $<0.001$ \\
\hline
\end{tabular}

IGF-1: insulin-like growth factor-1; IQR: interquartile range; Cl: confidence interval.

Table 4. Correlations between IGF-1 level and serum concentrations of cortisol and renin in ICU patients with sepsis

\begin{tabular}{|llcl}
\hline & Variable & Correlation (rho) & p-value \\
\hline Day 0 & Cortisol & -0.052 & 0.647 \\
& Renin & 0.044 & 0.700 \\
& Aldosterone & -0.015 & 0.896 \\
\hline \multirow{2}{*}{ Day 1 } & Glucagon & -0.159 & 0.218 \\
& Cortisol & -0.215 & 0.066 \\
& Renin & 0.005 & 0.965 \\
& Aldosterone & -0.087 & 0.456 \\
\hline \multirow{3}{*}{ Day 3 } & Glucagon & -0.136 & 0.317 \\
& Cortisol & -0.271 & 0.029 \\
& Renin & -0.258 & 0.038 \\
& Aldosterone & -0.052 & 0.684 \\
& Glucagon & 0.000 & 0.998 \\
\hline Day 7 & Cortisol & -0.221 & 0.140 \\
& Renin & -0.135 & 0.382 \\
& Aldosterone & 0.068 & 0.659 \\
\hline & Glucagon & 0.199 & 0.253 \\
\hline
\end{tabular}

IGF-1: insulin-like growth factor-1; ICU: intensive care unit.

portional hazards model was used to evaluate the effects of IGF-1, cortisol, and renin levels on survival (Table 3). This analysis of days $0,1,3$, and 7 was adjusted for age, sex, BMI, and SOFA score. With the exception of renin, the hormones did not significantly affect survival. How- ever, renin only affected survival on days 1 and 7, losing statistical significance on days 0 and 3 .

We further investigated the correlative relationship between IGF-1 level and cortisol, renin, aldosterone, and glucagon levels (Table 4). Serum cortisol level consistently showed a negative correlation with IGF-1 level, and this was significant on day $3(\mathrm{p}=0.029)$. The other hormones showed no distinct correlation with IGF-1 level.

\section{Discussion}

This study investigated changes in serum IGF-1, cortisol, and renin levels over time in a Korean population with sepsis or septic shock. Serum IGF-1 level was lower in patients with septic shock than in septic patients without shock. Furthermore, IGF-1 level tended to have a negative relationship with serum cortisol level.

IGF-1 is a single-chain polypeptide hormone mainly produced by the liver and stimulated by pituitary GH. It has an anabolic effect that slows the catabolic response. [21] IGF-1 also plays an important role in multiple aspects of immunity (both innate and acquired) and inflammatory disorders.[22] 
In our study, serum IGF-1 level was consistently lower in patients with septic shock than in sepsis patients without shock; however, this was not significant on the day of admission or on day 7. In pro-inflammatory conditions like sepsis, expression of many cytokines, including interleukin- 1 and tumor necrosis factor- $\alpha$, increases and can induce metabolic changes. As a result, $\mathrm{GH}$ and IGF-1 levels are decreased.[23] Altered pulsatile release and blood sampling at a non-standard time on the day of admission might explain the nonsignificant difference between sepsis and septic shock patients on day 0.[24] The significant difference in IGF-1 level on days 1 and 3 might indicate that this level increased toward normal in patients without shock, while it remained low in patients with shock. Ashare et al.[25] reported that pretreatment with IGF-1 or replacement of IGF-1 12 hours after infection improved hepatic bacterial clearance and overall survival in a mouse model. Therefore, the difference in IGF-1 level between the two groups in the present study suggests that early IGF-1 treatment could be a beneficial component of infection control in septic patients.

Previous studies showed mixed results when assessing the effect of GH on mortality. Some studies showed that a high $\mathrm{GH}$ level was significantly associated with increased mortality, while other studies did not.[26-29] Papastathi et al.[9] showed that mortality was not related with IGF-1, IGF-binding protein-3, or GH level. Furthermore, they reported that GH was not a prognostic marker of survival. Similarly, our study showed that IGF-1 level on day $0,1,3$, or 7 was not associated with survival.

However, we did observe that renin was significantly associated with mortality on days 1 and 7. Previous studies showed that the renin-angiotensin-aldosterone system (RAAS) is activated in sepsis patients, and that activated RAAS mediators were associated with microvascular dysfunction and organ disorders.[30,31] Salgado et al.[31] reported that administration of RAAS antagonists in the early phase of sepsis could protect against endothelial damage and organ failure and eventually reduce the mortality rate. Further studies are needed to exam the role of renin in sepsis.
Low-dose hydrocortisone is usually administered in the ICU to patients with septic shock who are unresponsive to volume trial and vasopressor administration. However, Volbeda et al.[32] conducted a systematic review and meta-analyses of 35 trials, including 4,682 patients, and reported no statistically significant effects of steroid therapy on mortality or adverse events in patients with systemic inflammatory response syndrome, sepsis, severe sepsis, or even septic shock. Our study supports those earlier findings. Although serum cortisol level was significantly different between sepsis patients and septic shock patients on days 1, 3, and 7, cortisol level was not significantly associated with mortality.

A previous study showed that IGF-1 level was negatively correlated with cortisol level and sepsis severity.[9] IGF-1 also reduces angiotensin level and apoptosis.[33] In our study, IGF-1 level was significantly negatively correlated with both cortisol and renin levels on day 3; however, on the other days, these correlations were not significant. This could be explained by different blood sampling times on the day of admission and disruption of hormone homeostasis within approximately 1 week in sepsis patients.

This study has some limitations. First, we did not evaluate hormones that are closely related to IGF-1. GH and IGF-binding protein-3 levels are closely associated with IGF-1 level. An analysis of these hormones might have provided additional information about the changes in IGF-1 level in sepsis patients. Second, the duration of sepsis before ICU admission was not evaluated in this study. Hormone levels are severely affected by the severity and duration of sepsis. Therefore, the duration of infection before ICU admission might have affected the results of our study. Well-designed prospective studies that consider the severity of sepsis and the duration of infection before ICU admission are therefore needed. Third, although we excluded patients with liver disease, we did not exclude those who had recently been prescribed corticosteroids or those with malignant disease or diabetes mellitus. While this could have affected our results, all of the study population was treated with an insulin protocol 
with a targeted glucose level of 100 to $140 \mathrm{mg} / \mathrm{dL}$, and their diet was managed by a specialized nutrition team.

In conclusion, we investigated whether the severity of sepsis was associated with changes in hormone levels in Korean ICU patients. Although IGF-1 level was lower in septic shock patients, this factor was not significantly associated with mortality. Septic shock patients also exhibited higher cortisol and renin levels relative to sepsis patients. Furthermore, renin level was significantly related with mortality on days 1 and 7. Prospective large-scale studies are needed to confirm the roles of these hormones in ICU patients.

\section{ORCID}

$\begin{array}{ll}\text { Sang Hoon Lee } & \text { http://orcid.org/0000-0002-7706-5318 } \\ \text { Kyung Soo Chung } & \text { http://orcid.org/0000-0003-1604-8730 } \\ \text { Eun Young Kim } & \text { http://orcid.org/0000-0002-3281-5744 } \\ \text { Ji Ye Jung } & \text { http://orcid.org/0000-0003-1589-4142 } \\ \text { Moo Suk Park } & \text { http://orcid.org/0000-0003-0820-7615 }\end{array}$

\section{References}

1) Assuncao MS, Teich V, Shiramizo SC, Araújo DV, Carrera RM, Serpa Neto A, et al: The cost-effectiveness ratio of a managed protocol for severe sepsis. J Crit Care 2014; 29: 692.e1-6.

2) Mouncey PR, Osborn TM, Power GS, Harrison DA, Sadique MZ, Grieve RD, et al: Trial of early, goaldirected resuscitation for septic shock. N Engl J Med 2015; 372: 1301-11.

3) ARISE Investigators; ANZICS Clinical Trials Group, Peake SL, Delaney A, Bailey M, Bellomo R, et al: Goal-directed resuscitation for patients with early septic shock. N Engl J Med 2014; 371: 1496-506.

4) ProCESS Investigators, Yealy DM, Kellum JA, Huang DT, Barnato AE, Weissfeld LA, et al: A randomized trial of protocol-based care for early septic shock. N Engl J Med 2014; 370: 1683-93.
5) Russell JA: Management of sepsis. N Engl J Med 2006; 355: 1699-713.

6) Vincent JL, Marshall JC, Namendys-Silva SA, François B, Martin-Loeches I, Lipman J, et al: Assessment of the worldwide burden of critical illness: the intensive care over nations (ICON) audit. Lancet Respir Med 2014; 2: 380-6.

7) Zhang Q, Dong G, Zhao X, Wang M, Li CS: Prognostic significance of hypothalamic-pituitary-adrenal axis hormones in early sepsis: a study performed in the emergency department. Intensive Care Med 2014; 40: 1499-508.

8) Bondanelli M, Zatelli MC, Ambrosio MR, degli Uberti EC: Systemic illness. Pituitary 2008; 11: 187-207.

9) Papastathi C, Mavrommatis A, Mentzelopoulos S, Konstandelou E, Alevizaki M, Zakynthinos S: Insulin-like growth factor I and its binding protein 3 in sepsis. Growth Horm IGF Res 2013; 23: 98-104.

10) Takala J, Ruokonen E, Webster NR, Nielsen MS, Zandstra DF, Vundelinckx G, et al: Increased mortality associated with growth hormone treatment in critically ill adults. N Engl J Med 1999; 341: 785-92.

11) Donmez R, Oren D, Ozturk G, Kisaoglu A, Ozogul B, Atamanalp SS: The combined effects of glutamine and growth hormone on intestinal anastomosis in the rat intra-abdominal sepsis model. J Surg Res 2013; 182: $142-5$.

12) Voerman HJ, van Schijndel RJ, Groeneveld AB, de Boer H, Nauta JP, van der Veen EA, et al: Effects of recombinant human growth-hormone in patients with severe sepsis. Ann Surg 1992; 216: 648-55.

13) Bjarnason R, Wickelgren R, Hermansson M, Hammarqvist F, Carlsson B, Carlsson LM: Growth hormone treatment prevents the decrease in insulin-like growth factor I gene expression in patients undergoing abdominal surgery. J Clin Endocrinol Metab 1998; 83: 1566-72.

14) Yue C, Wang W, Tian WL, Huang Q, Zhao RS, Zhao $\mathrm{YZ}$, et al: Lipopolysaccharide-induced failure of the gut barrier is site-specific and inhibitable by growth hormone. Inflamm Res 2013; 62: 407-15. 
15) Jaffa AA, Vio C, Velarde V, LeRoith D, Mayfield RK: Induction of renal kallikrein and renin gene expression by insulin and IGF-I in the diabetic rat. Diabetes 1997; 46: 2049-56.

16) Haddad GE, Blackwell K, Bikhazi A: Regulation of insulin-like growth factor-1 by the renin-angiotensin system during regression of cardiac eccentric hypertrophy through angiotensin-converting enzyme inhibitor and AT1 antagonist. Can J Physiol Pharmacol 2003; 81: 142-9.

17) Spicer LJ, Chamberlain CS: Influence of cortisol on insulin- and insulin-like growth factor 1 (IGF-1)induced steroid production and on IGF-1 receptors in cultured bovine granulosa cells and thecal cells. Endocrine 1998; 9: 153-61.

18) Weber MM, Simmler P, Fottner C, Engelhardt D: Insulin-like growth factor II (IGF-II) is more potent than IGF-I in stimulating cortisol secretion from cultured bovine adrenocortical cells: interaction with the IGF-I receptor and IGF-binding proteins. Endocrinology 1995; 136: 3714-20.

19) American-College of Chest Physicians Society of Critical Care Medicine Consensus Conference: definitions for sepsis and organ failure and guidelines for the use of innovative therapies in sepsis. Crit Care Med 1992; 20: 864-74.

20) Dellinger RP, Levy MM, Carlet JM, Bion J, Parker MM, Jaeschke R, et al: Surviving Sepsis Campaign: international guidelines for management of severe sepsis and septic shock: 2008. Crit Care Med 2008; 36: 296-327.

21) Lin MC, Leung SY, Fang WF, Chin $\mathrm{CH}$, Chung KF: Down-regulation of insulin-like growth factor I (IGF-I) in the mouse diaphragm during sepsis. Chang Gung Med J 2010; 33: 501-8.

22) Heemskerk VH, Daemen MA, Buurman WA: Insulin-like growth factor-1 (IGF-1) and growth hormone $(\mathrm{GH})$ in immunity and inflammation. Cytokine Growth Factor Rev 1999; 10: 5-14.

23) Dahn MS, Lange MP, Jacobs LA: Insulinlike growth factor-I production is inhibited in human sepsis.
Arch Surg 1988; 123: 1409-14.

24) Van den Berghe G: Endocrine changes in critically ill patients. Growth Horm IGF Res 1999; 9 Suppl A: 77-81.

25) Ashare A, Nymon AB, Doerschug KC, Morrison JM, Monick MM, Hunninghake GW: Insulin-like growth factor-1 improves survival in sepsis via enhanced hepatic bacterial clearance. Am J Respir Crit Care Med 2008; 178: 149-57.

26) Gianotti L, Broglio F, Aimaretti G, Arvat E, Colombo S, Di Summa M, et al: Low IGF-I levels are often uncoupled with elevated GH levels in catabolic conditions. J Endocrinol Invest 1998; 21: 115-21.

27) Frayn KN, Price DA, Maycock PF, Carroll SM: Plasma somatomedin activity after injury in man and its relationship to other hormonal and metabolic changes. Clin Endocrinol (Oxf) 1984; 20: 179-87.

28) Schuetz P, Müller B, Nusbaumer C, Wieland M, Christ-Crain M: Circulating levels of GH predict mortality and complement prognostic scores in critically ill medical patients. Eur J Endocrinol 2009; 160: 157-63.

29) de Groof F, Joosten KF, Janssen JA, de Kleijn ED, Hazelzet JA, Hop WC, et al: Acute stress response in children with meningococcal sepsis: important differences in the growth hormone/insulin-like growth factor I axis between nonsurvivors and survivors. J Clin Endocrinol Metab 2002; 87: 3118-24.

30) Doerschug KC, Delsing AS, Schmidt GA, Ashare A: Renin-angiotensin system activation correlates with microvascular dysfunction in a prospective cohort study of clinical sepsis. Crit Care 2010; 14: R24.

31) Salgado DR, Rocco JR, Silva E, Vincent JL: Modulation of the renin-angiotensin-aldosterone system in sepsis: a new therapeutic approach? Expert Opin Ther Targets 2010; 14: 11-20.

32) Volbeda M, Wetterslev J, Gluud C, Zijlstra JG, van der Horst ICC, Keus F: Glucocorticosteroids for sepsis: systematic review with meta-analysis and trial sequential analysis. Intensive Care Med 2015; 41: 1220-34. 
33) Kajstura J, Fiordaliso F, Andreoli AM, Li B, Chimenti S, Medow MS, et al: IGF-1 overexpression inhibits the development of diabetic cardiomyopathy and angiotensin II-mediated oxidative stress. Diabetes 2001; 50: 1414-24. 